\title{
Resveratrol Inhibits Monocytic Cell Chemotaxis to MCP-1 and Prevents Spontaneous Endothelial Cell Migration Through Rho Kinase-Dependent Mechanism
}

\author{
Iwona Cicha ${ }^{1}$, Melanie Regler ${ }^{1}$, Katharina Urschel ${ }^{1}$, Margarete Goppelt-Struebe ${ }^{2}$, Werner G. Daniel ${ }^{1}$ \\ and Christoph D. Garlichs ${ }^{1}$ \\ ${ }^{1}$ Department of Cardiology and Angiology, University of Erlangen-Nuremberg, Erlangen, Germany \\ ${ }^{2}$ Department of Nephrology and Hypertension, University of Erlangen-Nuremberg, Erlangen, Germany
}

\begin{abstract}
Aim: Inflammatory cell recruitment and intimal neovascularization contribute to atherosclerotic plaque destabilization. The anti-inflammatory red wine polyphenol, resveratrol, has been implicated in cardiovascular protection. In this study, we investigated the effects of resveratrol on endothelial and monocytic cell migration.

Methods: Human umbilical vein endothelial cell (EC) migration was assessed in a modified barrier assay. Chemotaxis of THP-1 monocytic cells towards monocyte chemoattractant protein (MCP)-1 was determined using a Boyden chamber. Erk phosphorylation downstream of MCP-1 receptor and activation of myosin phosphatase targeting subunit 1 (pMYPT1) downstream of Rho kinase were determined by Western blotting.

Results: In resveratrol-treated cells, progressive shape elongation was observed, evident after $6 \mathrm{~h}$ of treatment. Treatment with resveratrol $(1-20 \mu \mathrm{mol} / \mathrm{L})$ dose-dependently inhibited EC migration. This effect of resveratrol was independent of nuclear factor (NF)-kappaB and sirtuin 1, but was abrogated in the presence of Rho kinase inhibitors. Moreover, resveratrol induced pMYPT1 activation, indicating a novel mechanism of resveratrol activity in EC. In monocytic cells, treatment with resveratrol significantly inhibited chemotaxis towards MCP-1 already at $1 \mu \mathrm{mol} / \mathrm{L}$. At a resveratrol concentration of $10 \mu \mathrm{mol} / \mathrm{L}$, chemotaxis was reduced nearly to the negative control (unstimulated with MCP-1) levels. This effect was independent of NF-kappaB and RhoA signaling. In resveratroltreated monocytic cells, MCP-1-induced Erk phosphorylation downstream of CCR2 receptor was dose-dependently inhibited, as observed by Western blot analysis.

Conclusions: Resveratrol dose-dependently inhibited endothelial cell migration and MCP-1-induced monocytic cell chemotaxis. This activity may contribute to the cardioprotective effects of resveratrol by inhibition of intimal neovascularization and monocyte recruitment into the artery wall.
\end{abstract}

J Atheroscler Thromb, 2011; 18:1031-1042.

Key words; Resveratrol, Endothelial cell migration, RhoA, ROCK inhibition, Monocyte chemotaxis

\section{Introduction}

Atherosclerosis is a progressive inflammatory dis-

Address for correspondence: Iwona Cicha, Laboratory of Molecular Cardiology, Department of Cardiology and Angiology, University of Erlangen-Nuremberg, Schwabachanlage 10, 91054 Erlangen, Germany

E-mail: Iwona_Cicha@yahoo.com

Received: December 13, 2010

Accepted for publication: June 29, 2011 ease characterized by the formation of lipid-rich lesions protected by a fibrous cap containing immune cells, smooth muscle cells, and extracellular matrix ${ }^{1)}$. Monocytes/macrophages are inflammatory cell types that primarily infiltrate early atherosclerotic plaques upon activation of chemokine secretion ${ }^{2)}$. The accumulating macrophages not only contribute to lesion enlargement, but also release cytokines and chemokines that further drive the immune response and plaque progression ${ }^{3)}$. Over time, ongoing inflamma- 
tory cell accumulation and extracellular matrix degradation contribute to fibrous cap thinning, plaque destabilization and, potentially, rupture. Plaque angiogenesis plays an important role in the destabilization of atherosclerotic lesions. In advanced plaques, inflammatory cell infiltration, and the concomitant production of numerous pro-angiogenic cytokines may lead to the induction of uncontrolled intimal neovascularization, resulting in the production of immature and fragile (leaky) vasa vasorum ${ }^{4}$ ) similar to blood vessels seen in tumor development. These can serve as a port of entry for inflammatory cells, and contribute to the development of a hemorrhagic and rupture-prone environment. Increasing evidence suggests that intimal neovascularization is directly related to the stage of plaque development, the risk of plaque rupture, and subsequently, the acute clinical manifestations of atherosclerosis ${ }^{5}$.

As the inflammatory cell migration into the lesion and intimal neovascularization are considered crucial steps in the destabilization of atherosclerotic plaque, the inhibition of leukocyte and endothelial migration poses a challenge for effective anti-atherosclerotic therapy. Results of epidemiological studies that demonstrated an inverse correlation between dietary polyphenol intake and cardiovascular mortality (reviewed $\mathrm{in}^{6}$ ) suggest that the powerful antiinflammatory properties of plant polyphenols (e.g. resveratrol, curcumin, epicatechin) may induce the cardioprotective response. Resveratrol (trans-3,4',5trihydroxystilbene), the active compound of red wine, was previously shown to inhibit the activation of nuclear factor (NF) $-\kappa \mathrm{B}^{7)}$, a transcription factor which modulates the inflammatory response in endothelial cells. It was also associated with improved endothelium-dependent vasodilation in humans ${ }^{8)}$. Resveratrolinduced activation of sirtuin 1 (SIRT1) was shown to confer a vasoprotective phenotype in endothelial cells ${ }^{9)}$. Moreover, as shown in our previous study, treatment with resveratrol significantly prevented TNF- $\alpha$-induced adhesion molecule expression and monocytic cell adhesion to ECs exposed to non-uniform shear stress ${ }^{10)}$. Apart from the inhibition of inflammatory pathways, resveratrol was previously implicated in the inhibition of cancer cell migration ${ }^{11)}$ and tumor angiogenesis ${ }^{12)}$ indicating its ability to interfere with signal transduction pathways regulating cell motility. In the context of atherosclerosis, inhibition of vascular cell migration, in particular with regard to monocytes and endothelial cells, may contribute to reduced plaque progression. In this study, we therefore investigated the effects of resveratrol on spontaneous endothelial migration and MCP-1- induced monocytic cell chemotaxis.

\section{Methods}

\section{Materials and Reagents}

Endothelial Cell Growth Medium was obtained from Promo Cell (Heidelberg, Germany). Phosphatebuffered saline (PBS, pH 7.4) and RPMI 1640 medium were purchased from Biochrom AG (Berlin, Germany). Accutase ${ }^{\mathrm{TM}}$, penicillin, streptomycin, fetal calf serum (FCS), horse serum, and collagen-1 were from PAA Laboratories (Linz, Austria), and dispase was from Gibco (Eggenstein, Germany). TNF- $\alpha$ was purchased from Miltenyi Biotec (Bergisch Gladbach, Germany). Resveratrol (trans-3,4',5-trihydroxystilbene), obtained from Sigma (Munich, Germany), was dissolved in ethanol to $100 \mathrm{mmol} / \mathrm{L}$ concentration. Simvastatin, kindly provided by Merck (Rahway, NJ), was dissolved in ethanol and activated as described by Jakobisiak et al. ${ }^{13)}$. Rho kinase (ROCK) inhibitors, Y27632 and hydroxyfasudil, as well as forskolin, rolipram, and SIRT1 inhibitor III were from Calbiochem (Darmstadt, Germany). Cell-permeable selective Rho inhibitor (C3 Transferase from Clostridium botulinum) was purchased from Cytoskeleton Inc. (Denver CO, USA). To determine the appropriate C3 concentrations, the phenotypic changes (cell shape, actin cytoskeleton) were monitored over 6-30 h in HUVECs treated with C3 at $0.1-1 \mu \mathrm{g} / \mathrm{mL}$. Based on these studies, 2 concentrations were selected for the cell migration experiments $(0.25 \mu \mathrm{g} / \mathrm{mL}$ and $0.5 \mu \mathrm{g} / \mathrm{mL})$, which induced progressive phenotypic changes indicating effective Rho inhibition, but were well tolerated by the cells, i.e. did not induce marked cell toxicity after $24 \mathrm{~h}$ incubation. Monocyte chemoattractant protein-1 (MCP-1) was from Tebu-bio (Offenbach, Germany). NF- $\kappa$ B inhibitor BAY11-7082 ((E)-3-[(4methylphenyl)sulphonyl]-2-propenenitrile) from Biomol (Hamburg, Germany), was dissolved in DMSO to $100 \mathrm{mmol} / \mathrm{L}$ concentration. MAP Kinase Kinase (MEK) inhibitor, U0126, was from Promega (Madison, WI, USA).

Monoclonal rabbit anti-phospho-Erk antibody, rabbit anti-Erk1/2, and rabbit antibody against the phosphorylated form of myosin phosphatase targeting subunit 1 (pMYPT1, Thr853) were obtained from Cell Signaling (Danvers, MA, USA). Rabbit anti-vinculin antibody was from Santa Cruz (Heidelberg, Germany) and HRP-conjugated anti-rabbit antibody was purchased from Amersham (Freiburg, Germany).

\section{Cell Culture}

Human umbilical vein endothelial cells 
(HUVECs) were isolated from freshly collected umbilical cords by standard techniques and grown in supplemented endothelial cell growth medium in a humidified $7.5 \% \mathrm{CO}_{2}$ atmosphere. In all experiments, HUVECs at passage 1-2 were used.

THP-1 monocytic cells were cultured in RPMI 1640 medium supplemented with $2 \mathrm{mmol} / \mathrm{L}$ glutamine, $100 \mathrm{U} / \mathrm{mL}$ penicillin, $100 \mu \mathrm{g} / \mathrm{mL}$ streptomycin and $10 \%$ FCS. Cell viability was greater than $98 \%$ as estimated by Trypan blue exclusion.

\section{Immunofluorescent Staining}

The effects of resveratrol treatment on endothelial morphology were analyzed immunocytochemically. Briefly, HUVECs were fixed with $4 \%$ paraformaldehyde, followed by permeabilization with $0.2 \%$ Triton X-100 in PBS. Monoclonal antibody against vascular endothelial (VE)-cadherin (1:40) was obtained from Abcam (Cambridge, UK). F-actin fibers were visualized using Alexa 488-conjugated phalloidin (PromoKine, Heidelberg, Germany). Antimouse IgGs coupled to Alexa Fluor 555 were purchased from Molecular Probes (Karlsruhe, Germany).

Bright field photos were obtained using phase contrast. Fluorescent images were obtained using an inverted microscope (Zeiss Axiovert 100, Jena, Germany) combined with a digital camera, at $\times 200$ magnification.

As a measure of the cell shape change, the elongation index was employed: $\mathrm{EI}=(\mathrm{L}-\mathrm{S}) /(\mathrm{L}+\mathrm{S})$, where $\mathrm{L}$ is the length of the cell, and $\mathrm{S}$ the short axis. In each group, the long and the short axes of $>150 \mathrm{VE}$-cadherin-stained cells from 4 independent experiments were measured using computer-aided planimetry (Lucia Software V. 4.21; Laboratory Imaging Ltd., Nuremberg, Germany).

\section{Endothelial Cell Migration Assay}

HUVEC migration was assessed in a modified barrier assay using silicone cell culture inserts from Ibidi (Munich, Germany). HUVECs were seeded in 2 wells separated by a $500 \mu \mathrm{m}$ barrier, at a concentration of $3 \times 10^{5} / \mathrm{mL}$. The cells were treated with $1-20$ $\mu \mathrm{mol} / \mathrm{L}$ resveratrol overnight. Following the removal of inserts, HUVECs were washed with medium and incubated with appropriate concentrations of resveratrol for up to $24 \mathrm{~h}$. The gap between the 2 monolayers was recorded at the insert removal point $(0 \mathrm{~h})$, and at 3, 6,8 , and 24 hours using a Nikon CCD-camera connected to the Olympus IX70 microscope, at $\times 100$ magnification. Cell-free areas at different time points were measured using computer-aided planimetry (Lucia Software V. 4.21). The effect of resveratrol on cell migration was assessed by calculating the increase in the area occupied by cells at later time points compared with the cell-covered area at $0 \mathrm{~h}$. In all experiments, ethanol (at $0.02 \%$ ) was used as a control for the specificity of resveratrol effects.

\section{Chemotaxis Assay}

The effect of resveratrol $(1-10 \mu \mathrm{mol} / \mathrm{L}, 20 \mathrm{~h})$ on monocytic cell migration was assessed in a 48-well microchamber (NeuroProbe, Gaithersburg, MD, USA). Briefly, the lower wells were filled with $28 \mu \mathrm{L}$ serum-free RPMI 1640. MCP-1 $(50 \mathrm{ng} / \mathrm{mL})$ was used as a positive control. The upper wells were filled with $56 \mu \mathrm{L}$ resveratrol-treated monocytic cells at a concentration of $1 \times 10^{6}$ cells $/ \mathrm{mL}$, and separated from the lower compartment by an $8 \mu \mathrm{m}$-pore, collagen-coated polycarbonate membrane (Nucleopore; NeuroProbe). After incubation for $1 \mathrm{~h}$ at $37^{\circ} \mathrm{C}$, the membranes were fixed in methanol and stained in DiffQuick, before scraping off the cells on the upper side of the filter membrane. Migrated adherent cells were counted in 6 high-power microscopic fields for each well. Migrated non-adherent cells from the lower wells were counted using a Bürker-Türk counting chamber. All samples were run in quadruplicate and averaged. The mean number of migrated cells in the negative control (MCP-1 unstimulated) samples was set as 1. For collagen coating, the membranes were incubated in 20 $\mu \mathrm{mol} / \mathrm{L}$ collagen-1 at 37 for $1 \mathrm{~h}$. Ethanol-treated monocytic cells were used to confirm the specificity of resveratrol effects.

\section{Western Blotting}

To indirectly determine the activation of ROCK by resveratrol, HUVECs were incubated in the presence or absence of $10 \mu \mathrm{mol} / \mathrm{L}$ resveratrol for $60 \mathrm{~min}$. After treatment, the cells were washed with PBS. The lysis of cell pellets and subsequent Western blot analysis were carried out as described before ${ }^{14)}$. pMYPT1 was analyzed using a specific antibody $(1: 1000)$ overnight. To confirm equal protein loading, the membranes were re-probed with antibody against vinculin.

Monocytic cells were incubated overnight with 1-20 $\mu \mathrm{mol} / \mathrm{L}$ resveratrol, followed by the stimulation with $50 \mathrm{ng} / \mathrm{mL} \mathrm{MCP-1} \mathrm{for} 10 \mathrm{~min}$. After treatment, the activation of Erk was analyzed using appropriate antibodies (anti-pErk 1:1000; anti-Erk1/2 1:1000; overnight), and visualized using an enhanced chemiluminescence system (ECL-Plus; Amersham).

\section{Statistical Analyses}

Data are expressed as the mean \pm SEM, unless stated otherwise. $P<0.05$ was considered statistically 
significant. Analyses were carried out using SigmaStat ${ }^{\circledR}$ software. The paired $t$-test and Mann-Whitney rank sum test were used to compare the differences between resveratrol-treated and control samples.

\section{Results}

Resveratrol Induces a Dose- and Time-Dependent Change in Endothelial Morphology

HUVECs treated with growing concentrations of resveratrol displayed progressive elongation as compared with control cells. Cell elongation was associated with the rearrangement of cell-cell contacts visualized by VE-cadherin staining (Fig. 1A). As a measure of the cell shape change, we employed the elongation index $(\mathrm{EI}=(\mathrm{L}-\mathrm{S}) /(\mathrm{L}+\mathrm{S}))$, where EI values close to 1 indicate cell elongation, whereas values close to 0 indicate a rounded cell shape. Following $24 \mathrm{~h}$ of treatment with $10 \mu \mathrm{mol} / \mathrm{L}$ resveratrol (Fig. 1B), HUVECs were markedly elongated $(E I=0.56 \pm 0.02)$ in contrast to control cells, which were characterized by a rounded cell shape $(E I=0.25 \pm 0.01)$. Regarding the timecourse of the observed changes, the cell shape differences between control and resveratrol-treated cells become apparent after $6 \mathrm{~h}$ of treatment, indicating a long-term effect on the endothelial cytoskeleton (Fig. 1B).

\section{RhoA/ROCK are Involved in Endothelial Cell Elongation upon Resveratrol Treatment}

To investigate if resveratrol-induced endothelial cell elongation is related to its $\mathrm{NF}-\kappa \mathrm{B}$ inhibitory activity, HUVECs were treated with a specific inhibitor of NF- $\kappa$ B pathway BAY11-7082 (1 $\mu \mathrm{mol} / \mathrm{L})$. BAY117082 was selected for its effectiveness, as it was previously shown to completely abolish TNF- $\alpha$-induced expression of endothelial adhesion molecules (10); however, treatment of HUVECs with BAY11-7082 did not evoke any shape changes (not shown), indicating that endothelial cell elongation by resveratrol was not mediated by NF- $\kappa \mathrm{B}$ inhibition. In contrast, when HUVECs were incubated with $10 \mu \mathrm{mol} / \mathrm{L}$ resveratrol in the presence of $1 \mu \mathrm{mol} / \mathrm{L}$ simvastatin or ROCK inhibitors (Y27632 at $10 \mu \mathrm{mol} / \mathrm{L}$, or hydroxyfasudil at $20 \mu \mathrm{mol} / \mathrm{L}$ ), resveratrol-induced elongation was prevented (Fig. 1C), indicating a role of active RhoA in this process. Increased intracellular cAMP was previously shown to inhibit RhoA activation by its phosphorylation on a serine residue ${ }^{15)}$. In agreement with this, treatment with a combination of two cAMP-inducing agents, forskolin $(5 \mu \mathrm{mol} / \mathrm{L})$ and rolipram $(10 \mu \mathrm{mol} / \mathrm{L})$, abolished the formation of cell-spanning F-actin fibers and prevented cell elonga- tion in response to resveratrol (Fig. 1C).

\section{Resveratrol Inhibits Spontaneous Endothelial Cell Migration in a ROCK-Dependent Manner}

The effect of resveratrol on endothelial cell migration was assessed in a modified barrier assay. HUVECs were cultured in two separated wells for 24 $\mathrm{h}$, followed by treatment with $1-20 \mu \mathrm{mol} / \mathrm{L}$ resveratrol overnight. After removal of the barrier, cells were allowed to migrate for up to $27 \mathrm{~h}$ in the presence of appropriate concentrations of resveratrol. As shown in Fig. 2A-B, treatment with resveratrol dose-dependently inhibited endothelial cell migration, with a statistically significant reduction at $5 \mu \mathrm{mol} / \mathrm{L}(p=0.016)$, as compared to untreated, or ethanol-treated control cells (Fig. 2B at 24h).

The effect of resveratrol on endothelial cell migration was not related to its NF- $\kappa \mathrm{B}$ inhibitory activity, as treatment with NF- $\kappa \mathrm{B}$ inhibitor BAY11-7082 did not affect migration (cell-covered area at 24h: $79 \pm 8 \%$ versus $86 \pm 3 \%$ in control samples). Also, inhibition of SIRT1, endothelial sirtuin, which is activated by resveratrol and involved in vessel growth control, did not significantly reverse the effect of resveratrol: The cellcovered area at $24 \mathrm{~h}$ in samples treated with resveratrol in the presence of SIRT1-Inhibitor III $(1 \mu \mathrm{mol} / \mathrm{L})$ was $43 \pm 4 \%$, as compared with $40 \pm 4 \%$ in samples treated with resveratrol only. Blocking ROCK activity was shown to activate angiogenesis in vitro and in vivo ${ }^{16)}$; therefore, we investigated if inhibition of ROCK signaling induces spontaneous endothelial cell migration and whether it can interfere with the anti-migratory effect of resveratrol. In control cells, inhibition of ROCK with hydroxyfasudil $(20 \mu \mathrm{mol} / \mathrm{L}$; Fig. 3A $)$ significantly induced spontaneous migration. A similar, albeit slightly weaker effect was observed in cells treated with Y27632 (cell-covered area at 24 h: $94 \pm$ $5 \%$ versus $86 \pm 3 \%$ in control samples, Fig. 3A). To test whether Rho/ROCK signaling is involved in the resveratrol effect on endothelial cell migration, HUVECs were treated with $10 \mu \mathrm{mol} / \mathrm{L}$ resveratrol in the presence of ROCK inhibitors, specific cell-permeable Rho inhibitor (C3 transferase, $0.25 \mu \mathrm{g} / \mathrm{mL}$ ), or simvastatin $(1 \mu \mathrm{mol} / \mathrm{L})$. Under these conditions, the anti-migratory effect of resveratrol was strongly reversed by inhibition of ROCK either by hydroxyfasudil or by Y27632 (Fig. 3A). Comparable results were obtained with the Rho inhibitor C3 transferase (cellcovered area at $24 \mathrm{~h}: 73 \pm 8 \%$ versus $40 \pm 4 \%$ in resveratrol-treated samples, Fig. 3B). In contrast, treatment with simvastatin was less effective (Fig. 3B). This was likely related to the fact that statins inhibit isoprenylation of other GTPases critically involved in cell 
A

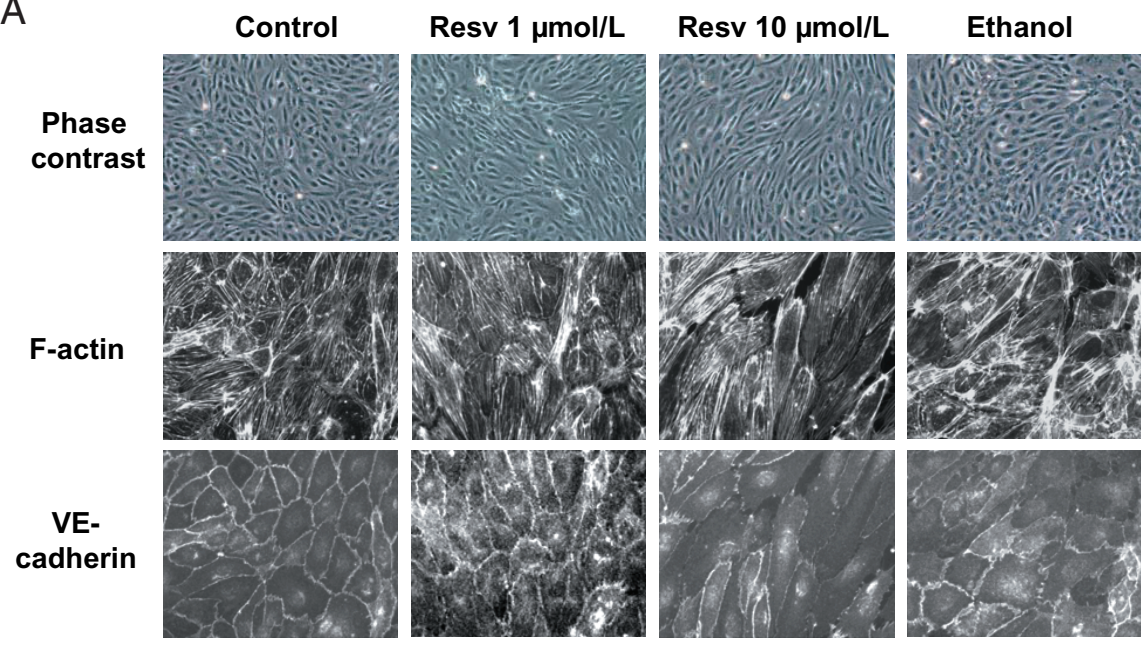

B
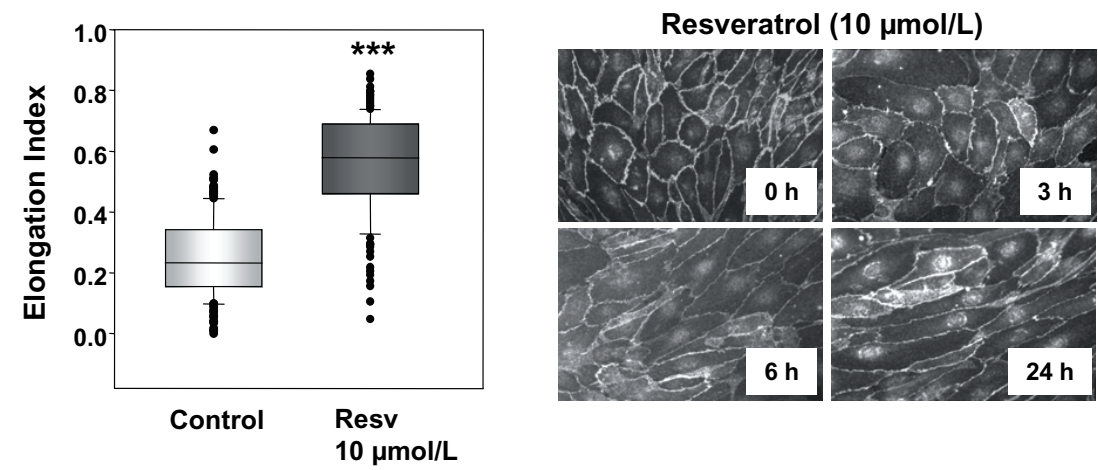

C
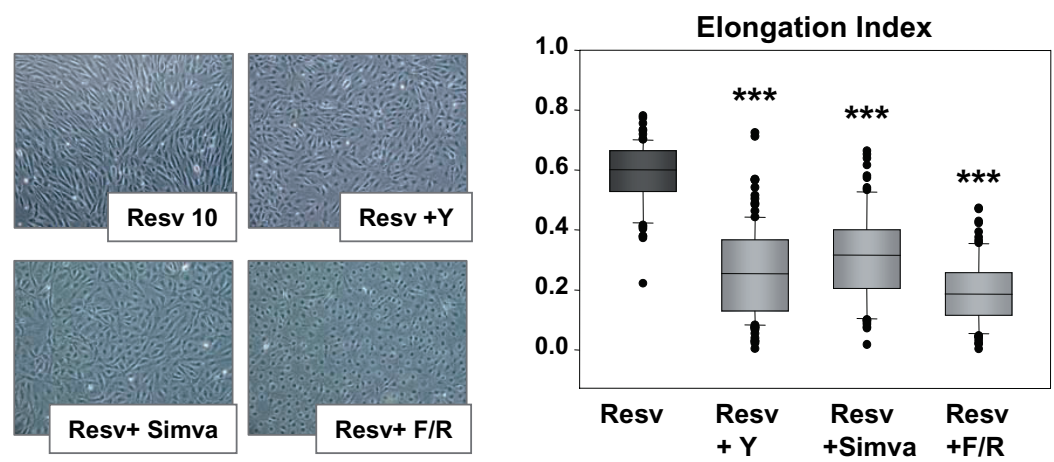

Fig. 1. Effects of resveratrol on endothelial cell shape.

A. Resveratrol affects endothelial cell morphology. Phase contrast $(\times 150$; top panel $)$ and fluorescent images $(\times 200)$ are representative of 4 independent experiments; Actin cytoskeleton (middle panel) and cell-cell contacts (bottom panel) were visualized using Alexa488-conjugated phalloidin and anti-VE-cadherin antibody, respectively.

B. Differences in cell elongation between control and resveratrol (Resv, $10 \mu \mathrm{mol} / \mathrm{L})$ treated cells. Left panel: Elongation index, EI $=(\mathrm{L}-\mathrm{S}) /(\mathrm{L}$ $+S)$ of treated cells: EI values close to 1 indicate cell elongation, whereas values close to 0 indicate rounded cell shape. Graph shows the median, 10th, 25th 75th, and 90th percentile. In each group, $>150$ cells from 4 independent experiments were measured. ${ }^{* * *} p<0.001$ versus control; $t$-test.

Right panel: Time course of resveratrol $(10 \mu \mathrm{mol} / \mathrm{L})$ effect on endothelial shape elongation; Phase contrast images $(\times 100)$ were obtained with Lucia software. Photos are representative of 3 independent experiments.

C. Resveratrol-induced endothelial cell elongation is prevented by RhoA inhibition. HUVECs were treated with $10 \mu \mathrm{mol} / \mathrm{L}$ resveratrol (Resv) for $24 \mathrm{~h}$ in presence of $\mathrm{Y} 27632(\mathrm{Y}, 10 \mu \mathrm{mol} / \mathrm{L}$ ), simvastatin (Simva, $1 \mu \mathrm{mol} / \mathrm{L}$ ), and forskolin and rolipram $(\mathrm{F} / \mathrm{R}, 5$ and $10 \mu \mathrm{mol} / \mathrm{L}$, respectively). Left panel: Phase contrast images $(\times 100)$ representative of 4 independent experiments. Right panel: Elongation index of treated cells. Graph shows the median, 10th, 25th 75th, and 90th percentile. In each group, $>80$ cells from 3 independent experiments were measured. $*_{* * *} p<0.001$ versus resveratrol-treated cells; $t$-test. 
A
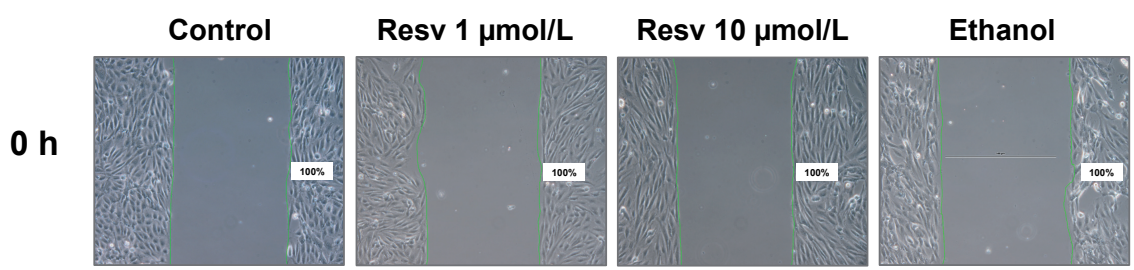

$24 \mathrm{~h}$
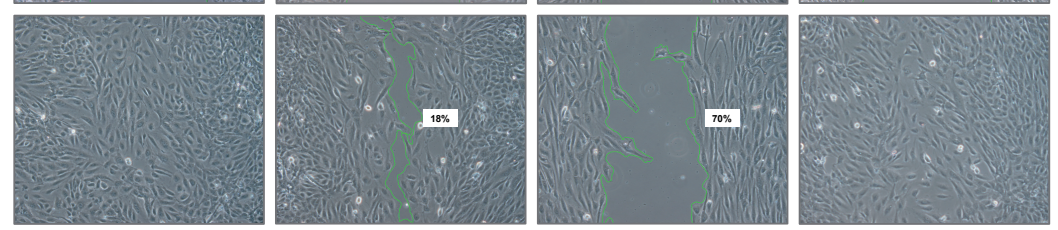

\section{$\mathrm{B}$}
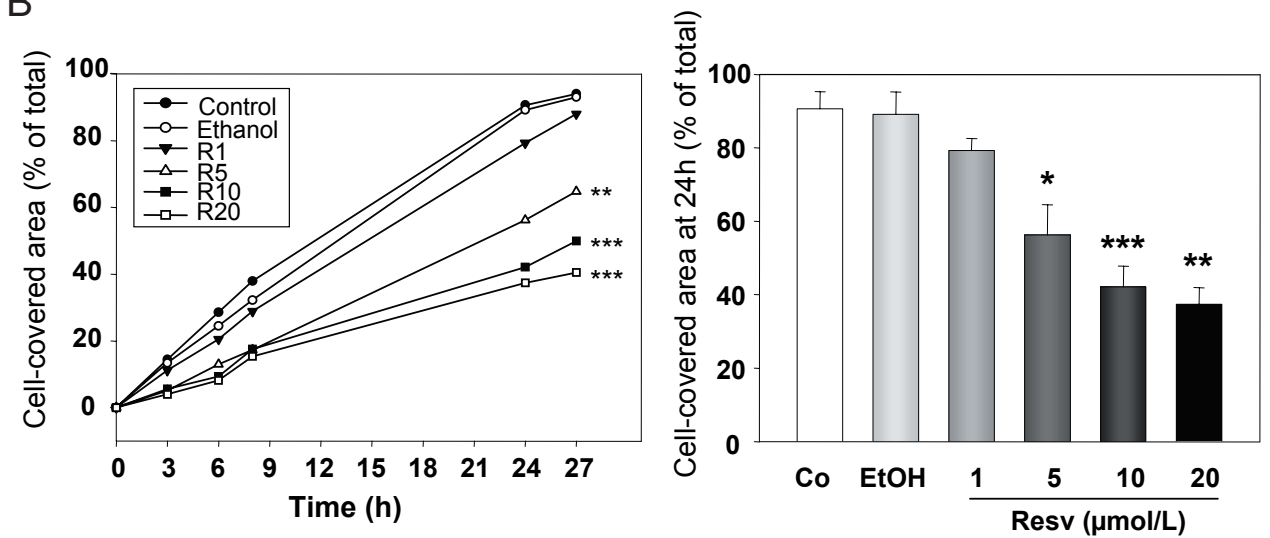

Fig. 2. Effects of resveratrol on endothelial cell migration.

A. Resveratrol dose-dependently inhibits unstimulated endothelial cell migration. Phase contrast images $(\times 100)$ were obtained with Lucia software. Photos are representative of 6 independent experiments.

B. Data quantification: Left panel: Time-course of endothelial cell migration upon treatment with different concentrations of resveratrol; Right panel: Cell-covered area at $24 \mathrm{~h}$ after insert removal. Data are expressed as the mean \pm SEM of $4-8$ independent experiments. ${ }^{*} p<0.05,{ }^{* *} p<0.01,{ }^{* * *} p<0.001$ versus control; Mann-Whitney rank sum test.

migration, e.g. Rac, or Cdc42 ${ }^{17)}$, thus blocking cell motility by preventing lamellipodia and filopodia formation. To confirm whether resveratrol exerts an activating effect on endothelial ROCK signaling, we determined the phosphorylation of MYPT1, a downstream target of ROCK. As shown in Fig. 3C, treatment with resveratrol significantly induced MYPT1 phosphorylation in endothelial cells. This induction was abolished in the presence of a ROCK inhibitor, hydroxyfasudil.

\section{Resveratrol Inhibits Monocytic Cell Chemotaxis to MCP-1}

Relatively high concentrations of resveratrol (10-100 $\mu \mathrm{mol} / \mathrm{L})$ were previously shown to prevent MCP-1 binding to CCR2 in THP-1 monocytic cells ${ }^{18)}$; however, no functional studies have been performed. We therefore investigated whether resveratrol inhibits monocytic chemotaxis to MCP-1. As shown in Fig. 4A-B, resveratrol $(1-10 \mu \mathrm{mol} / \mathrm{L})$ reduced monocytic cell chemotaxis towards MCP-1 in a dosedependent manner. There was a statistically significant reduction in the number of migrated adherent cells already at $1 \mu \mathrm{mol} / \mathrm{L}$ of resveratrol $(n=4, p<0.02$ vs control samples). At $10 \mu \mathrm{mol} / \mathrm{L}$ resveratrol, the chemotactic response to $\mathrm{MCP}-1$ was reduced nearly to levels comparable with the negative control without chemoattractant ( $>90 \%$ reduction; $n=4, p=0.002$ vs positive control, Fig. 4A). The same pattern was observed when the numbers of transmigrated nonadherent cells in the lower wells were analyzed.

To prove that the observed inhibition of mono- 
A

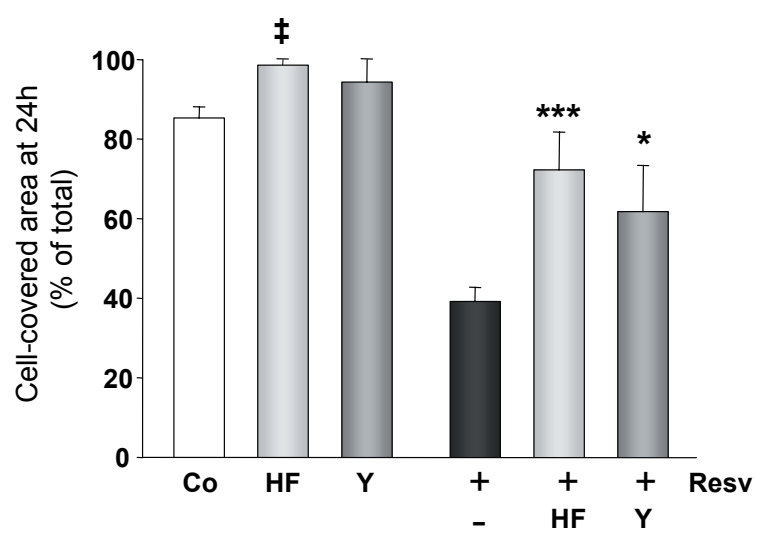

B

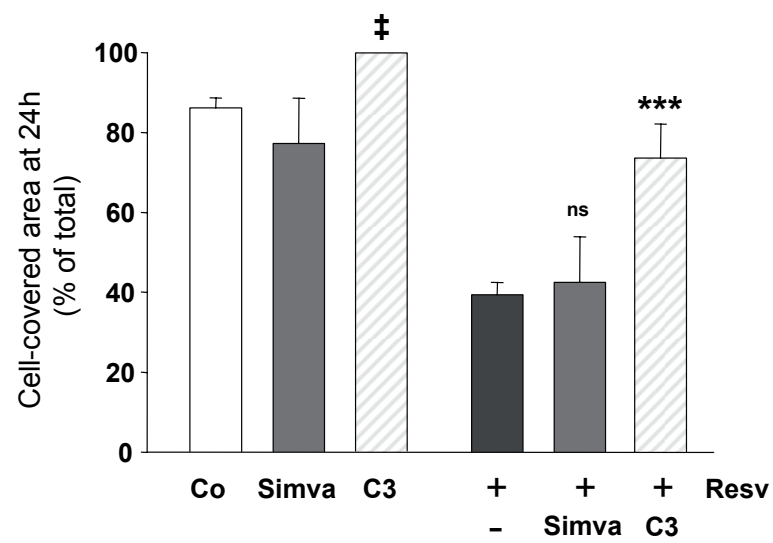

C

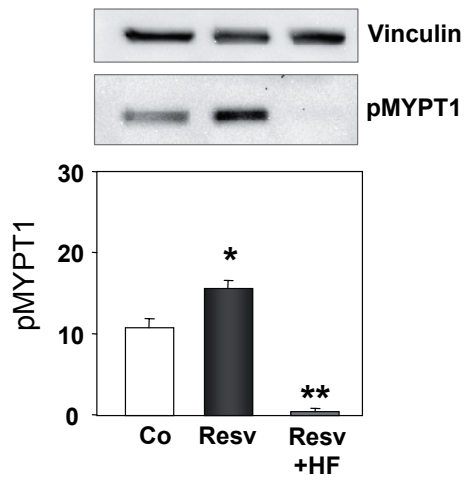

cytic cell migration is resveratrol-specific, an appropriate concentration of ethanol was used as a control. As shown in Fig. 4, treatment with ethanol did not affect monocytic cell chemotaxis to MCP-1. Furthermore, resveratrol-mediated inhibition of monocytic cell chemotaxis was independent of NF- $\kappa \mathrm{B}$, as treatment with NF- $\kappa$ B inhibitor BAY11-7082 did not affect chemotaxis. Neither ROCK inhibitors nor cAMP-inducing agents prevented the resveratrol effect on monocytic cell chemotaxis, indicating that its suppressive effect is not mediated by RhoA/ROCK activation (Fig. 4C).
Fig.3. Resveratrol prevents endothelial migration in a ROCKdependent manner.

A. Resveratrol-induced inhibition of endothelial cell migration is reduced by ROCK inhibition. HUVECs were treated with $20 \mu \mathrm{mol} / \mathrm{L}$

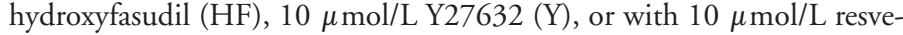
ratrol (Resv) in the presence of hydroxyfasudil or Y27632. Cell-covered area at $24 \mathrm{~h}$ after insert removal is shown. Data are expressed as the mean \pm SEM of $4-6$ independent experiments. ${ }^{\star} p<0.05$ versus control; ${ }^{*} p<0.05,{ }^{* * *} p<0.001$ versus $10 \mu \mathrm{mol} / \mathrm{L}$ resveratrol; Mann-Whitney rank sum test.

B. Selective Rho inhibition reduces the anti-migratory effect of resveratrol in endothelial cells. HUVECs were treated with $1 \mu \mathrm{mol} / \mathrm{L}$ simvastatin (Simva), $0.25 \mu \mathrm{g} / \mathrm{mL} \mathrm{C3} \mathrm{transferase} \mathrm{(C3),} \mathrm{or} \mathrm{with} 10 \mu \mathrm{mol} / \mathrm{L}$ resveratrol (Resv) in the presence of simvastatin or C3. Cell-covered area at $24 \mathrm{~h}$ after insert removal is shown. Data are expressed as the mean \pm SEM of 3-4 independent experiments. ${ }^{\star} p<0.05$ versus control; *** $p<$ 0.001 versus $10 \mu \mathrm{mol} / \mathrm{L}$ resveratrol; ns, not significant; Mann-Whitney rank sum test.

C. Resveratrol induces MYPT1 phosphorylation downstream of ROCK. HUVECs were treated with $10 \mu \mathrm{mol} / \mathrm{L}$ resveratrol (Resv) for $60 \mathrm{~min}$. In the presence of hydroxyfasudil (HF, $20 \mu \mathrm{mol} / \mathrm{L}$ ), pMYPT1 induction was prevented. Upper panel: Blots representative of 4 independent experiments are shown. Lower panel: Data quantification. Graph shows the median $\left( \pm\right.$ SEM) of 4 independent experiments. ${ }^{*} p<0.05$ versus control; ${ }^{* *} p<0.01$ versus Resv; $t$-test.

Binding of MCP-1 to CCR2 on monocytes leads to rapid activation of Ras and to Erk phosphorylation $^{19)}$; therefore, we investigated the effect of resveratrol treatment on Erk phosphorylation upon MCP-1 stimulation. For this purpose, monocytic cells were pretreated with different concentrations of resveratrol overnight followed by stimulation with $50 \mathrm{ng} / \mathrm{mL}$ MCP-1 for $10 \mathrm{~min}$. As shown in Fig. 5A, resveratrol dose-dependently inhibited Erk phosphorylation upon MCP-1 activation. At $50 \mu \mathrm{mol} / \mathrm{L}$ resveratrol, Erk phosphorylation was reduced to levels comparable 

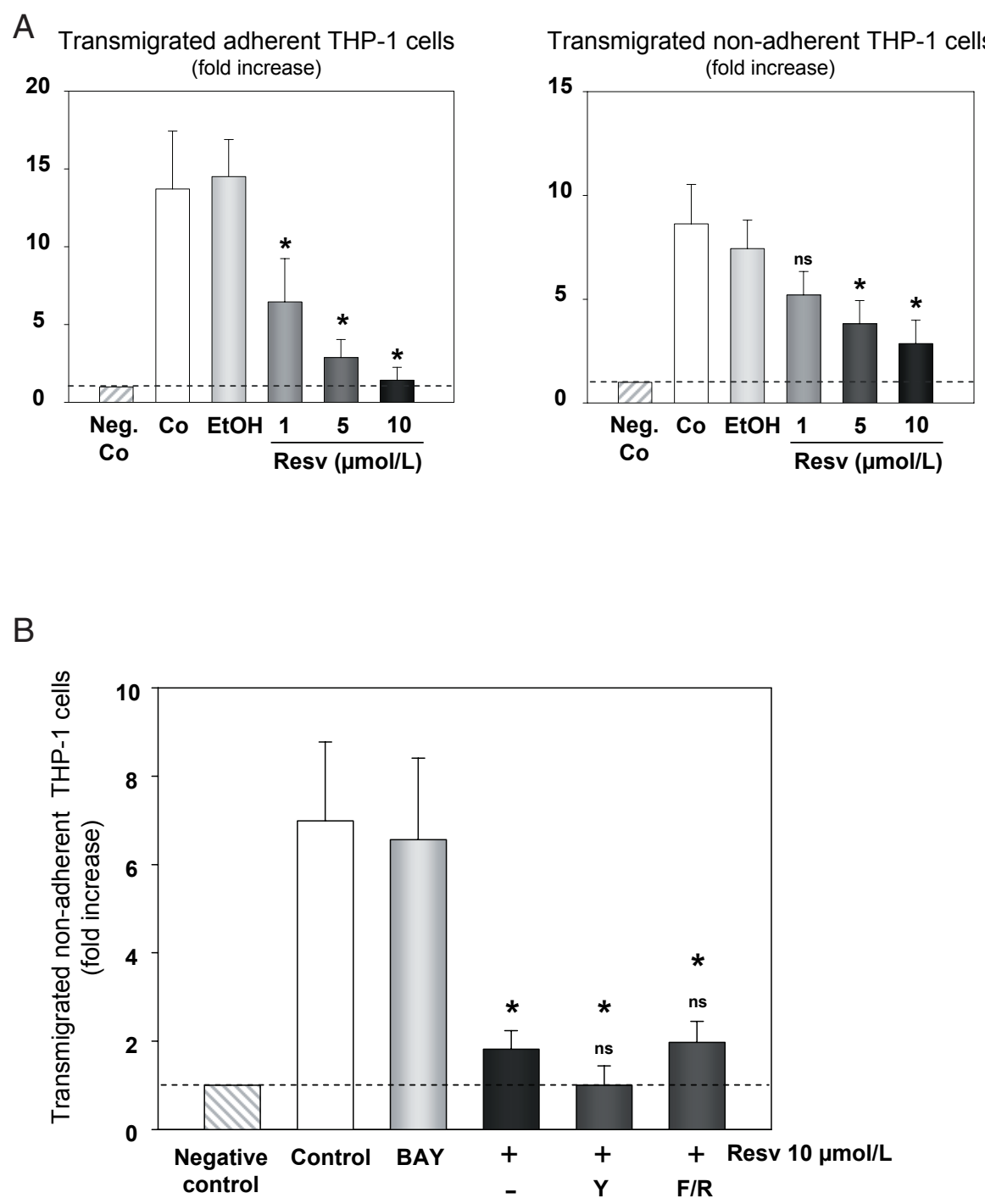

Fig.4. Effects of resveratrol on monocytic cell migration.

A. Resveratrol dose-dependently inhibits monocytic cell chemotaxis towards MCP-1. Left panel: Adherent transmigrated THP-1 cells were counted in 6 high-power microscopic fields for each well. Right panel: Non-adherent transmigrated cells from the lower wells were counted using Bürker-Türk counting chamber. Striped bar represents negative control. The mean number of migrated cells in the negative control (MCP-1 unstimulated) samples was set as 1. ${ }^{*} p<0.05$ versus positive control (Co); ns, not significant; Mann-Whitney rank sum test, $n=4$. B. Resveratrol-induced inhibition of monocytic migration is independent of NF- $\kappa$ B activation, ROCK signaling, or cAMP levels. THP-1 cells were treated with $1 \mu \mathrm{mol} / \mathrm{L}$ BAY11-7082 or with $10 \mu \mathrm{mol} / \mathrm{L}$ resveratrol in the presence of either Y27632 (Y; $10 \mu \mathrm{mol} / \mathrm{L}$ ), or forskolin and rolipram (F/R; 5 and $10 \mu \mathrm{mol} / \mathrm{L}$, respectively). Graph shows the mean ( \pm SEM) numbers of non-adherent transmigrated monocytic cells in 3-5 independent experiments. ${ }^{*} p<0.05$ versus control; ns, not significant versus $10 \mu \mathrm{mol} / \mathrm{L}$ resveratrol; Mann-Whitney rank sum test.

with negative control samples unstimulated with MCP-1. To investigate whether blocking Erk phosphorylation is sufficient to inhibit MCP-1-induced chemotaxis, the effect of MEK inhibitor U0126 on monocytic cell migration was analyzed. U0126 (50 $\mu \mathrm{mol} / \mathrm{L})$ significantly inhibited the chemotaxis of
THP-1 cells, albeit to a smaller degree than $10 \mu \mathrm{mol} / \mathrm{L}$ resveratrol (Fig. 5B). In cells treated with U0126 in the presence of resveratrol, a synergistic effect of both substances was observed, and the number of transmigrated THP-1 cells was reduced nearly to zero. 


\section{Discussion}

Resveratrol, the potent anti-inflammatory compound of red wine, has been recently shown to delay atherosclerotic lesion formation in ApoE-deficient mice ${ }^{20)}$. With regard to endothelial function, the majority of the atheroprotective activity of resveratrol was thus far believed to originate from the inhibition of pro-inflammatory signaling via suppression of NF- $\kappa \mathrm{B}$ activity $^{7,21,22)}$. In accordance with this, we previously demonstrated that resveratrol significantly inhibited adhesion molecule induction and monocytic cell adhesion to TNF- $\alpha$-stimulated endothelial cells under hemodynamic conditions corresponding to these in atherosclerosis-prone arterial bifurcations ${ }^{10)}$. The current data show that this compound affects endothelial cell morphology and strongly suppresses spontaneous endothelial cell migration. Migration of endothelial cells leads to vessel proliferation and their extension into the intimal regions of atherosclerotic plaque; therefore, inhibition of endothelial migration within growing lesions should contribute to the more effective prevention of plaque progression and its clinical consequences. Pharmacological inhibition of angiogenesis in atherosclerotic plaques, with ensuing inhibition of lesion progression, has been achieved in animal models ${ }^{23}$, 24). In spite of these promising in vivo studies, clinical attempts to inhibit neovascularization in the atherosclerotic arterial wall have been few thus $\mathrm{far}^{25)}$. Resveratrol was implicated in the inhibition of tumor neovascularization by recent studies ${ }^{12)}$, but the mechanisms of its anti-angiogenic effect are far from understood. Resveratrol was shown to activate SIRT1, the main endothelial sirtuin ${ }^{26)}$, which is known to control vessel growth under ischemic conditions ${ }^{27)}$; however, as SIRT1-dependent deacetylation either inhibits anti-angiogenic effects of FoxO1 ${ }^{28)}$, or activates pathways inducing cell migration, such as cortactin ${ }^{29)}$, SIRT1 is unlikely to be involved in the resveratrolinduced inhibition of migration. In a very recent study it was shown that resveratrol effect on injuryinduced choroidal neovascularization was independent of SIRT1, and mediated at least in part via AMPK activation ${ }^{30)}$. In accordance with these data, our results showed that SIRT1 inhibition did not abolish the inhibitory effect of resveratrol on endothelial cell migration.

One of the proposed cellular mechanisms of antiangiogenic activity of resveratrol is related to the reported binding and inhibition of integrin $\alpha \mathrm{V} \beta 3$ by resveratrol ${ }^{31)}$, which results in the inhibition of sprouting and tube formation ${ }^{32)}$. In the present study, we demonstrated that an additional mechanism involving
A
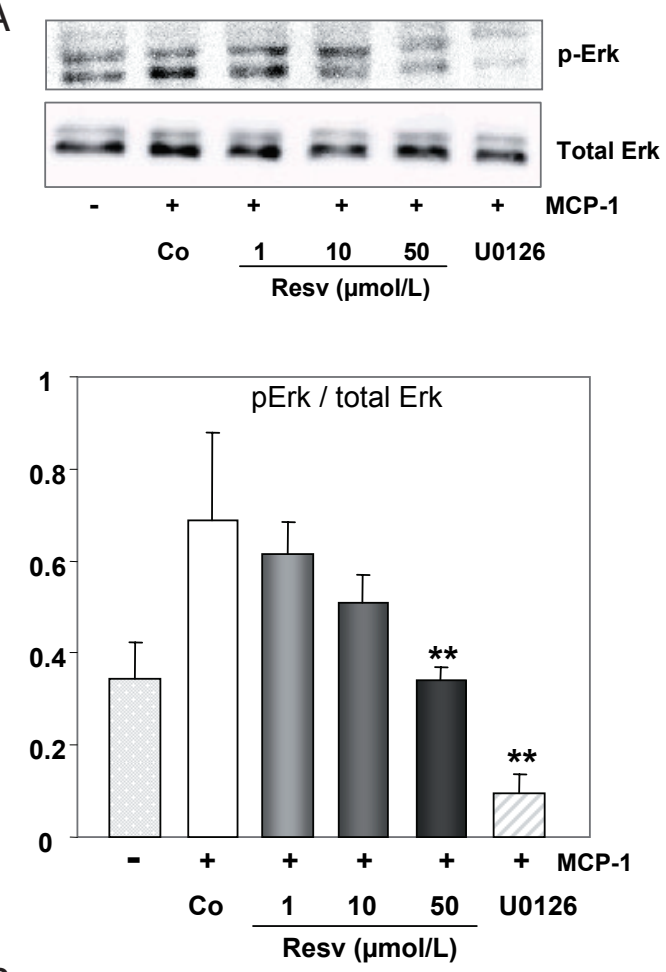

B

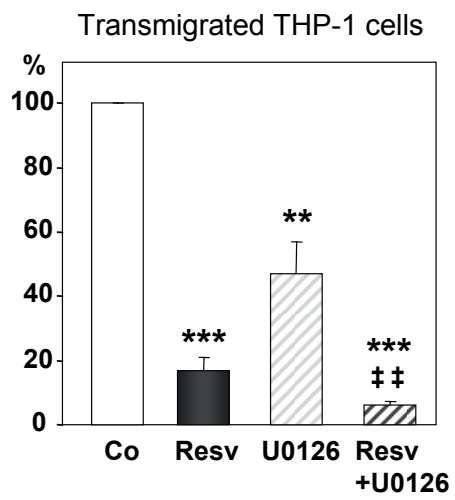

Fig. 5. Effects of resveratrol on Erk phosphorylation in monocytic cells.

A. MCP-1-induced Erk phosphorylation downstream of CCR2 is inhibited by resveratrol. THP-1 cells were treated with 1-50 $\mu \mathrm{mol} / \mathrm{L}$ resveratrol overnight and stimulated with MCP-1 (50 $\mathrm{ng} / \mathrm{mL}$ ) for $10 \mathrm{~min}$. THP-1 cells pretreated with MEK inhibitor U0126 $(50 \mu \mathrm{mol} / \mathrm{L} ; 2 \mathrm{~h})$ were used as an additional negative control. Upper panel: Blots representative of 4 independent experiments are shown. Lower panel: Data quantification: ratio of pErk to total Erk is shown. Graph shows the mean ( \pm SEM) of 4-6 independent experiments. ${ }^{* *} p<0.01$ versus control; Mann-Whitney rank sum test.

B. Blocking Erk phosphorylation inhibits MCP-1 induced chemotaxis. THP-1 cells were treated with $50 \mu \mathrm{mol} / \mathrm{L} \mathrm{MEK} \mathrm{inhibitor}$ $\mathrm{U} 0126,10 \mu \mathrm{mol} / \mathrm{L}$ resveratrol (Resv), or the combination of both. Numbers of transmigrated MCP-1-stimulated control cells was set to $100 \%$. Graph shows the mean $( \pm$ SEM) of 5 independent experiments. ${ }^{* *} p<0.01,{ }^{* * *} p<0.001$ versus positive control (Co); ${ }_{\mathrm{t}} p<0.01$ versus Resv; paired $t$-test. 
the ROCK pathway can contribute to the inhibitory activity of resveratrol on endothelial cell migration. As the inhibition of ROCK induces angiogenesis in vitro and in vivo ${ }^{16)}$, its activation by resveratrol would be expected to suppress endothelial migration; however, a recently published study on endothelium-denuded aortic rings suggested that resveratrol inhibits ROCK activity and reduces the phosphorylation of MYPT1 in smooth muscle cells ${ }^{33)}$. As data regarding resveratrol effects on ROCK pathway activation in endothelial cells have been missing, we investigated endothelial pMYPT1 levels, showing the induction of pMYPT1 in unstimulated endothelial cells upon treatment with resveratrol. These data clearly indicate that resveratrol exhibits cell-specific activity, inducing divergent pathways in different vascular cell types. With regard to endothelial cell migration, it must be noted that resveratrol-induced MYPT1 phosphorylation was nearly completely abolished in the presence of hydroxyfasudil. In contrast, the inhibition of endothelial migration by resveratrol was only partly prevented by ROCK inhibitors, indicating the existence of other, ROCK-independent pathway(s), targeted by resveratrol in endothelial cells. Thus, activation of ROCK signaling by resveratrol may represent an additional pathway modulating spontaneous endothelial cell migration. In contrast to specific ROCK inhibitors, little effect on the inhibition of endothelial migration by resveratrol was observed when the cells were treated with simvastatin. This was not unexpected, as the inhibition of protein isoprenylation by statins affects, apart from RhoA, several other Rho GTPases essential for cell migration ${ }^{17)}$, e.g. Rac, which affects lamellipodia formation, or Cdc42 responsible for filopodia extension. Although further studies are required to investigate the inter-relationship of specific endothelial pathways involved in the anti-angiogenic effects of resveratrol, the activation of ROCK signaling may represent one of the mechanisms contributing to the anti-migratory activity of this compound.

Apart from the inhibition of plaque neovascularization, significant protection from atherosclerosis can be achieved by inhibiting monocyte chemotaxis, as evidenced by studies in mice deficient in either MCP-1 ${ }^{34)}$ or its receptor CCR2 ${ }^{35)}$. Resveratrol has been previously reported to inhibit interleukin $1 \beta$ induced endothelial production of $\mathrm{MCP}-1^{36}$, and to prevent MCP-1 binding to CCR2 in THP-1 monocytic cells ${ }^{18)}$. We have demonstrated that these effects translate into functional suppression of monocytic cell migration towards MCP-1, with statistically significant inhibition already at $1 \mu \mathrm{mol} / \mathrm{L}$ resveratrol. This effect was independent of $\mathrm{NF}-\kappa \mathrm{B}$ inhibitory activity of resveratrol, and was not prevented by inhibition of the RhoA/ROCK pathway. In MCP-1 signaling downstream of CCR2, rapid Erk activation followed by the activation of integrins and chemotaxis was described ${ }^{19)}$. The inhibition of Erk is thus expected to prevent monocytic cell migration. As shown in our study, resveratrol treatment was associated with the dose-dependent inhibition of Erk phosphorylation upon MCP-1 stimulation; however, resveratrol suppressed monocytic cell chemotaxis to a greater degree than a specific inhibitor of Erk phosphorylation U0126, indicating that inhibition of Erk phosphorylation represents only one of the pathways involved in the anti-chemotactic effect of resveratrol. In light of existing in vivo data on the role of MCP-1 in atherosclerosis, inhibition of MCP-1-stimulated monocytic cell migration by resveratrol, and the extent of this effect, may represent one of the most important mechanisms of its cardioprotective activity.

With regard to resveratrol bioavailability, it must be noted that although the anti-inflammatory activity of resveratrol was observed already at $100 \mathrm{nmol} / \mathrm{L}$ concentrations in vitro ${ }^{7}$, much higher doses (10-100 $\mu \mathrm{mol} / \mathrm{L})$ were needed to inhibit cancer cell migration $^{11)}$, or to activate SIRT ${ }^{9}{ }^{\text {). }}$. After the intake of 300 $\mathrm{mL}$ red wine rich in stilbenes, peak stilbene concentration in plasma was reported to reach $10 \mu \mathrm{mol} / \mathrm{L}$, or about $4 \mu \mathrm{mol} / \mathrm{L}$ resveratrol ${ }^{6}$, although glucuronidation in the liver may reduce the bioavailability of the free compound to nanomolar concentrations. As dietary flavonoids were shown to inhibit the glucuronidation of resveratrol in human liver ${ }^{37)}$ thus improving its bioavailability, resveratrol concentrations used in the present study, although somewhat higher than achievable with red wine intake, are within the levels achievable with diet supplements containing higher doses (gram levels) of this compound. Moreover, its apparent pharmacologic safety ${ }^{38,20)}$, along with increased understanding of its pleiotropic activities, may help optimize the use of resveratrol in the treatment and prevention of cardiovascular disease.

In conclusion, the considerable preventive and therapeutic potential of resveratrol in atherosclerotic disease merits wider recognition. Suppression of endothelial and monocytic migration, as well as the previously reported inhibition of leukocyte-endothelial interactions, represent important mechanisms in resveratrol-mediated atheroprotection. Clinical studies will be necessary to determine whether these in vitro effects of resveratrol can translate into a long-term cardiovascular benefit associated with persisting plaque regression. 


\section{Acknowledgments}

This work was supported in part by the ELANProgram of the University of Erlangen-Nuremberg. The technical help of Nina Jaziri, Doris Flick, and Heike Kloos is gratefully acknowledged.

\section{References}

1) Hansson GK: Inflammation, atherosclerosis, and coronary artery disease. N Engl J Med, 2005; 352: 1685-1695

2) Weber C, Zernecke A, Libby P: The multifaceted contributions of leukocyte subsets to atherosclerosis: lessons from mouse models. Nat Rev Immuno, 2008; 8: 802-815

3) Liehn EA, Zernecke A, Postea O, Weber C: Chemokines: inflammatory mediators of atherosclerosis. Arch Physiol Biochem, 2006; 112: 229-238

4) Le Dall J, Ho-Tin-Noé B, Louedec L, Meilhac O, Roncal C, Carmeliet P, Germain S, Michel JB, Houard X: Immaturity of microvessels in haemorrhagic plaques is associated with proteolytic degradation of angiogenic factors. Cardiovasc Res, 2010; 85: 184-193

5) McCarthy MJ, Loftus IM, Thompson MM, Jones L, London NJ, Bell PR, Naylor AR, Brindle NP: Angiogenesis and the atherosclerotic carotid plaque: an association between symptomatology and plaque morphology. J Vasc Surg, 1999; 30: 261-268

6) Opie LH, Lecour S: The red wine hypothesis: from concepts to protective signalling molecules. Eur Heart J, 2007; 28: 1683-1693

7) Csiszar A, Smith K, Labinskyy N, Orosz Z, Rivera A, Ungvari Z: Resveratrol attenuates TNF- $\alpha$-induced activation of coronary arterial endothelial cells: role of NF- $\kappa \mathrm{B}$ inhibition. Am J Physiol Heart Circ Physiol, 2006; 291: H1694-H1699

8) Rakici O, Kiziltepe U, Coskun B, Aslamaci S, Akar F: Effects of resveratrol on vascular tone and endothelial function of human saphenous vein and internal mammary artery. Int J Cardiol, 2005; 105: 209-215

9) Gracia-Sancho J, Villarreal G Jr, Zhang Y, García-Cardeña G: Activation of SIRT1 by resveratrol induces KLF2 expression conferring an endothelial vasoprotective phenotype. Cardiovasc Res, 2010; 85: 514-519

10) Cicha I, Beronov K, Lopez Ramirez E, Osterode K, Goppelt-Struebe M, Raaz D, Yilmaz A, Daniel WG, Garlichs $\mathrm{CD}$ : Shear stress preconditioning modulates endothelial susceptibility to circulating TNF- $\alpha$ and monocytic cell recruitment in a simplified model of arterial bifurcations. Atherosclerosis, 2009; 207: 93-102

11) Azios NG, Dharmawardhane SF: Resveratrol and estradiol exert disparate effects on cell migration, cell surface actin structures, and focal adhesion assembly in MDA-MB-231 human breast cancer cells. Neoplasia, 2005; 7: 128-140

12) Kimura Y, Sumiyoshi M, Baba K: Antitumor activities of synthetic and natural stilbenes through antiangiogenic action. Cancer Sci, 2008; 99: 2083-2096

13) Jakobisiak M, Bruno S, Skierski JS, Darzynkiewicz Z: Cell cycle-specific effects of lovastatin. Proc Natl Acad Sci
USA, 1991; 88: 3628-3632

14) Cicha I, Yilmaz A, Klein M, Raithel D, Brigstock DR, Daniel WG, Goppelt-Struebe M, Garlichs CD: Connective tissue growth factor is overexpressed in complicated atherosclerotic plaques and induces mononuclear cell chemotaxis in vitro. Arterioscler Thromb Vasc Biol, 2005; 25: $1008-1013$

15) Tamma G, Klussmann E, Procino G, Svelto M, Rosenthal W, Valenti G: cAMP-induced AQP2 translocation is associated with RhoA inhibition through RhoA phosphorylation and interaction with RhoGDI. J Cell Sci, 2003; 116: $1519-1525$

16) Kroll J, Epting D, Kern K, Dietz CT, Feng Y, Hammes HP, Wieland T, Augustin HG: Inhibition of Rho-dependent kinases ROCK I/II activates VEGF-driven retinal neovascularization and sprouting angiogenesis. Am J Physiol Heart Circ Physiol, 2009; 296: H893-H899

17) Mason JC: Statins and their role in vascular protection. Clin Sci (Lond), 2003; 105: 251-266

18) Cullen JP, Morrow D, Jin Y, von Offenberg Sweeney N, Sitzmann JV, Cahill PA, Redmond EM: Resveratrol inhibits expression and binding activity of the monocyte chemotactic protein-1 receptor, CCR2, on THP-1 monocytes. Atherosclerosis, 2007; 195: e125-e133

19) Jiménez-Sainz MC, Fast B, Mayor F Jr, Aragay AM: Signaling pathways for monocyte chemoattractant protein 1-mediated extracellular signal-regulated kinase activation. Mol Pharmacol, 2003; 64: 773-782

20) Norata GD, Marchesi P, Passamonti S, Pirillo A, Violi F, Catapano AL: Anti-inflammatory and anti-atherogenic effects of cathechin, caffeic acid and trans-resveratrol in apolipoprotein E deficient mice. Atherosclerosis, 2007; 191: 2 65-271

21) Fan E, Zhang L, Jiang S, Bai Y: Beneficial effects of resveratrol on atherosclerosis. J Med Food, 2008; 11: 610-614

22) Inanaga $K$, Ichiki $T$, Matsuura $H$, Miyazaki R, Hashimoto T, Takeda K, Sunagawa K: Resveratrol attenuates angiotensin II-induced interleukin-6 expression and perivascular fibrosis. Hypertens Res, 2009; 32: 466-471

23) Moulton KS, Heller E, Konerding MA, Flynn E, Palinski W, Folkman J: Angiogenesis inhibitors endostatin or TNP-470 reduce intimal neovascularization and plaque growth in apolipoprotein E-deficient mice. Circulation, 1999; 99: 1726-1732

24) Ganaha F, Kao EY, Wong H, Elkins CJ, Lee J, Modanlou S, Rhee C, Kuo MD, Yuksel E, Cifra PN, Waugh JM, Dake MD: Stent-based controlled release of intravascular angiostatin to limit plaque progression and in-stent restenosis. J Vasc Interv Radiol, 2004; 15: 601-608

25) Stefanadis C, Toutouzas K, Stefanadi E, Tsiamis E, Vavuranakis M, Kipshidze N: Avastin-eluting stent: longterm angiographic and clinical follow up. Hellenic J Cardiol, 2008; 49: 188-190

26) Kaeberlein M, McDonagh T, Heltweg B, Hixon J, Westman EA, Caldwell SD, Napper A, Curtis R, DiStefano PS, Fields S, Bedalov A, Kennedy BK: Substrate-specific activation of sirtuins by resveratrol. J Biol Chem, 2005; 280: 17038-17045

27) Guarani V, Potente M: SIRT1 - a metabolic sensor that controls blood vessel growth. Curr Opin Pharmacol, 
2010; 10: 139-145

28) Potente M, Ghaeni L, Baldessari D, Mostoslavsky R, Rossig L, Dequiedt F, Haendeler J, Mione M, Dejana E, Alt FW, Zeiher AM, Dimmeler S: SIRT1 controls endothelial angiogenic functions during vascular growth. Genes Dev, 2007; 21: 2644-2658

29) Zhang Y, Zhang M, Dong H, Yong S, Li X, Olashaw N, Kruk PA, Cheng JQ, Bai W, Chen J, Nicosia SV, Zhang X: Deacetylation of cortactin by SIRT1 promotes cell migration. Oncogene, 2009; 28: 445-460

30) Khan AA, Dace DS, Ryazanov AG, Kelly J, Apte RS: Resveratrol regulates pathologic angiogenesis by a eukaryotic elongation factor-2 kinase-regulated pathway. Am J Pathol, 2010; 177: 481-492

31) Lin HY, Lansing L, Merillon JM, Davis FB, Tang HY, Shih A, Vitrac X, Krisa S, Keating T, Cao HJ, Bergh J, Quackenbush S, Davis PJ: Integrin $\alpha \mathrm{V} \beta 3$ contains a receptor site for resveratrol. FASEB J, 2006; 20: 1742-1744

32) Belleri M, Ribatti D, Savio M, Stivala LA, Forti L, Tanghetti E, Alessi P, Coltrini D, Bugatti A, Mitola S, Nicoli S, Vannini V, Presta M: Alphavbeta3 Integrin-dependent antiangiogenic activity of resveratrol stereoisomers. Mol Cancer Ther, 2008; 7: 3761-3770

33) Je HD, Lee MH, Jeong JH, Park SY, Sohn UD: Protective effect of resveratrol on agonist-dependent regulation of vascular contractility via inhibition of rho-kinase activity.
Pharmacology, 2010; 86: 37-43

34) Ishibashi $M$, Hiasa $K$, Zhao Q, Inoue S, Ohtani K, Kitamoto S, Tsuchihashi M, Sugaya T, Charo IF, Kura S, Tsuzuki T, Ishibashi T, Takeshita A, Egashira K: Critical role of monocyte chemoattractant protein-1 receptor CCR2 on monocytes in hypertension-induced vascular inflammation and remodeling. Circ Res, 2004; 94: 1203-1210

35) Ohman MK, Wright AP, Wickenheiser KJ, Luo W, Russo HM, Eitzman DT: Monocyte chemoattractant protein-1 deficiency protects against visceral fat-induced atherosclerosis. Arterioscler Thromb Vasc Biol, 2010, in press, DOI: 10.1161/ATVBAHA.110.205914

36) Cullen JP, Morrow D, Jin Y, Curley B, Robinson A, Sitzmann JV, Cahill PA, Redmond EM: Resveratrol, a polyphenolic phytostilbene, inhibits endothelial monocyte chemotactic protein-1 synthesis and secretion. J Vasc Res, 2007; 44: 75-84

37) de Santi C, Pietrabissa A, Spisni R, Mosca F, Pacific GM: Glucuronidation of resveratrol, a natural product present in grape and wine, in the human liver. Xenobiotica, 2000; 30: 1047-1054

38) Aggarwal BB, Bhardwaj A, Aggarwal RS, Seeram NP, Shishodia S, Takada Y: Role of resveratrol in prevention and therapy of cancer: preclinical and clinical studies. Anticancer Res, 2004; 24: 2783-2840 